\title{
Autotransplantation of a Premolar with Incipient Root Development, an 18-Year Follow-Up
}

\author{
José Luis MEJÍA-CARDONA, Maytté MARCANO-CALDERA, Jorge VERA, Asgeir SIGURDSSON
}

\section{ABSTRACT}

In young patients, premature tooth loss in the anterior maxilla after trauma is challenging for the patient and the dental professional, with serious implications from aesthetic and functional points of view, as well as from a craniofacial growth aspect perspective. Premolars autotransplanted into the maxillary anterior region have been shown to be a biological alternative in this situation. This report describes the clinical management of a case of premature loss of a maxillary central incisor after traumatic injury. A mandibular premolar at the stage of initial root development was transplanted into the alveolar socket of the lost incisor. After 18 years, the transplanted tooth remained responsive to pulp sensibility tests and the periradicular bone and soft tissues were within normal limits. Autotransplantation of premolar teeth into the maxilla could be considered an excellent treatment choice with many biological advantages over implants or fixed dentures as long as proper case selection is followed.

Keywords: Dental trauma, ridge preservation, root development, tooth autotransplantation

\section{HIGHLIGHTS}

- In young patients, premolar autotransplantation to replace lost teeth in the maxillary anterior region has proven to be an acceptable therapeutic alternative.

- In this case, a premolar in the early stage (one-fourth) of root development was autotransplanted and the transplanted tooth exhibited pulpal healing, continued root development, and maintenance of periodontal health with a normal alveolar process for 18 years.

- Tooth autotrasplantation has many biological advantages over implants or fixed dentures as long as proper case selection is followed.

\section{INTRODUCTION}

In young patients, premolar autotransplantation to replace lost teeth in the maxillary anterior region has proven to be an acceptable therapeutic alternative with good potential to induce bone growth and to re-establish a normal alveolar process (1-3).

Prognosis in these cases is improved when the transplanted tooth has a partially developed root, because it will allow for pulp revascularization and proper development of the root with closure of the foramen (3-5), thereby reducing the likelihood of requiring endodontic therapy with its associated additional costs and possible complications.

This type of treatment should be taken into consideration because of the biological advantages it provides, such as reported good long-term prognosis in patients during the early stages of maxillary development as well as in adults with prosthetic and/or orthodontic needs (6-8).

In this case, a premolar in the early stage (one-fourth) of root development was autotransplanted and the transplanted tooth exhibited pulpal healing, continued root development, and maintenance of periodontal health with a normal alveolar process for 18 years. 


\section{CASE PRESENTATION}

In November 1997, a 9-year-old boy presented at our dental office 2 weeks after dentoalveolar trauma, where he lost his maxillary left central incisor. The patient's parents reported he had had no medical problems. Adjacent teeth did not show any signs or symptoms of damage from the trauma, and they responded normally to electrical and thermal pulp tests. In the mandible, premolar eruption had started because of early loss of the primary molars due to caries. Radiographically, the alveolar socket of the maxillary left central incisor showed no remnants of root fragments, and the maxillary right central and maxillary left lateral incisors showed radiographic signs of almost complete root formation (Figure 1a).
The patient's mother wanted the lost tooth to be replaced, so the possibility of autotransplantation was considered. An orthodontist evaluated the case and suggested using the mandibular right second premolar, whose root was about onefourth formed (Figure 1b). The procedure and all of its risks were explained to the patient and his mother and informed consent was signed attained.

For the recipient site in the maxilla, anaesthetic without vasoconstrictor was used (Pricanest; Ropsohn Therapeutics Labs., Bogotá, Colombia). The alveolar socket of the maxillary central incisor was prepared by removing the granulation tissue without curettage of the socket walls. Extraction
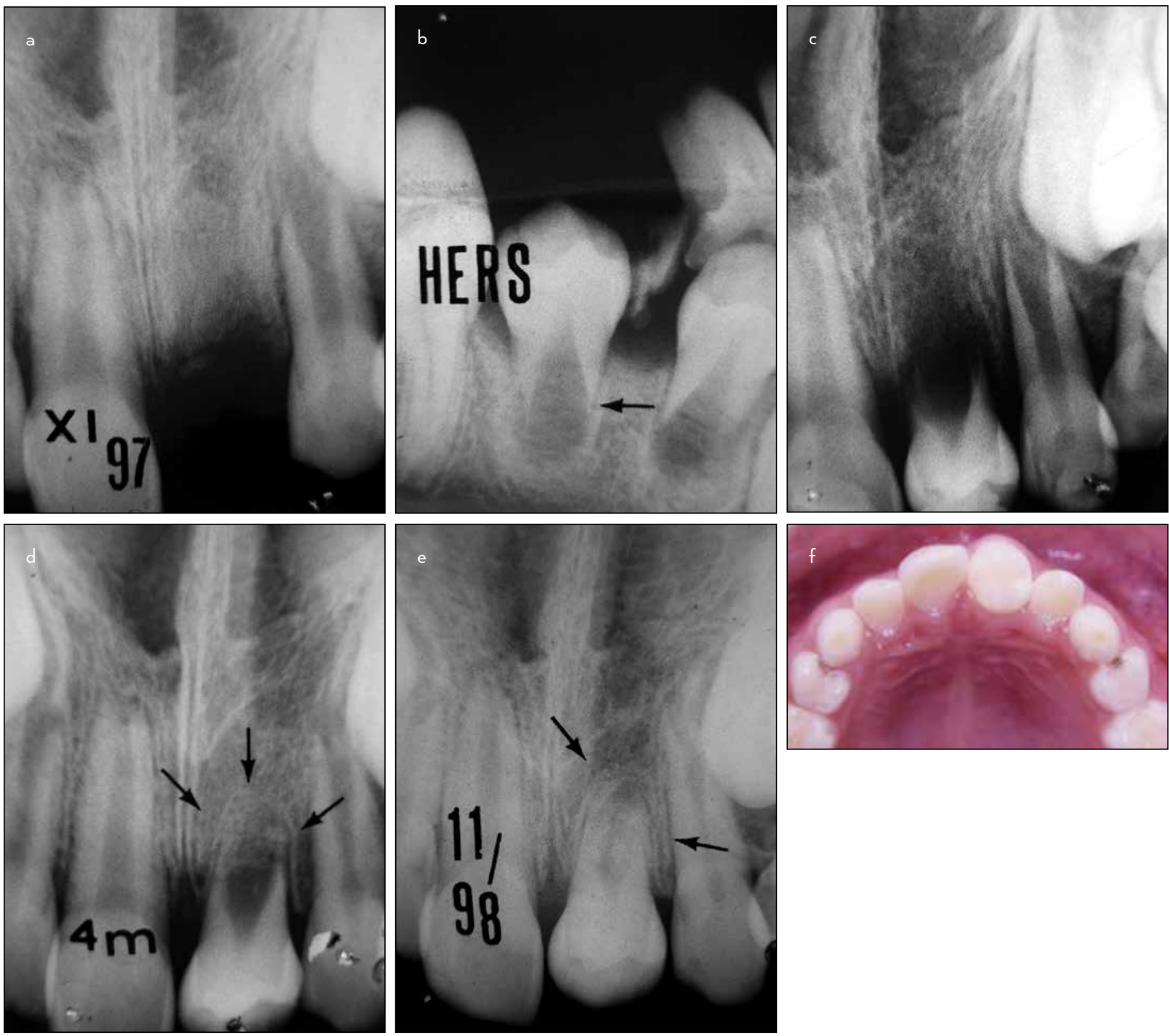

Figure 1. a-f. Initial radiograph of alveolar socket of maxillary left central incisor (a) radiograph of mandibular right second premolar to be transplanted. One-fourth of radicular development is present (b) Radiograph after autotransplantation to the recipient alveolar socket (c) Radiograph at 4-month follow-up. Some evidence of lamina dura adjacent to root growth (arrows) (d) Radiograph at 1-year follow-up. Bone crest height is normal, root development continues, and dentin apposition in the root canal can also be seen (e) Oclusal view of the premolar. Complete eruption is expected before the crown is restored $(f)$ 

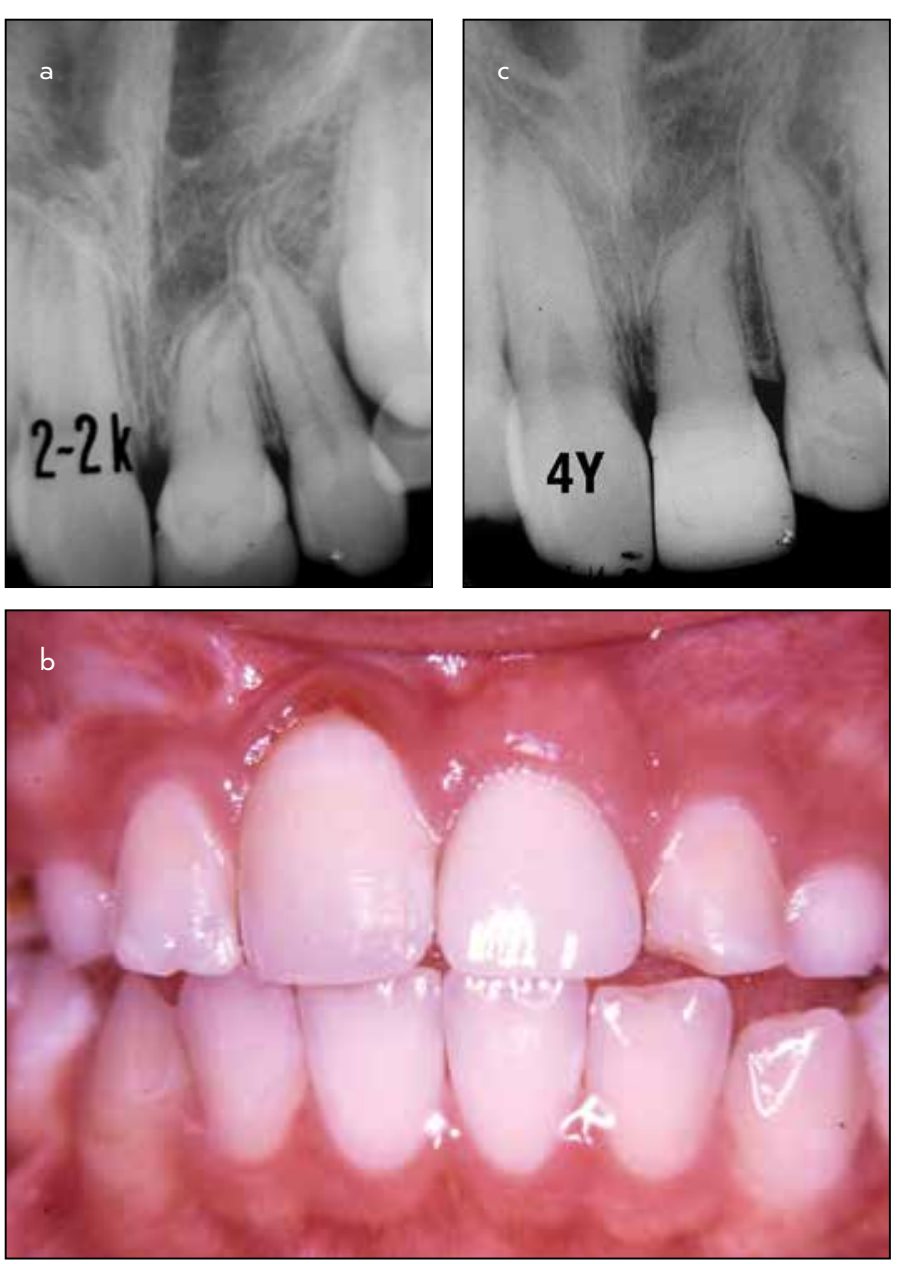

Figure 2. a-c. 2 years 3-months follow-up. Radiographically, there is absence of periodontal or periapical pathosis, but presence of lamina dura and hard tissue formation in the root canal (a) 2 years 3-months follow-up. Clinical picture with a ceramic restoration. Papilla and periodontal tissues look healthy (b) 4-year follow-up. Radiographically, periradicular tissues are normal and show no signs of inflammatory external root resorption. Hard tissue apposition seems to continue in the root canal space, which usually indicates vital tissue in the root canal (c)

of the mandibular premolar was performed, also using a local anaesthetic without vasoconstrictor, to minimise the effect on pulpal blood flow to the donor tooth. An intrasulcular incision was made around the mandibular premolar, which was then carefully luxated to avoid excessive rotation of the tooth and consequent damage to Hertwig's epithelial root sheath.

Once extracted, the premolar was immediately placed in the recipient alveolar socket, stabilized with 4-0 sutures and fixed in position with a nylon splint and composite resin for 6 weeks. Postoperative instructions were given to the patient and his mother. The tooth was kept out of occlusion to allow for radicular growth (Figure 1c).

At 6 weeks, the tooth was periodontally stable, so the splint was removed. Figure $1 \mathrm{~d}$-e shows the root development during the first year. The premolar crown was maintained intact until root formation and eruption were complete (Figure 1f).
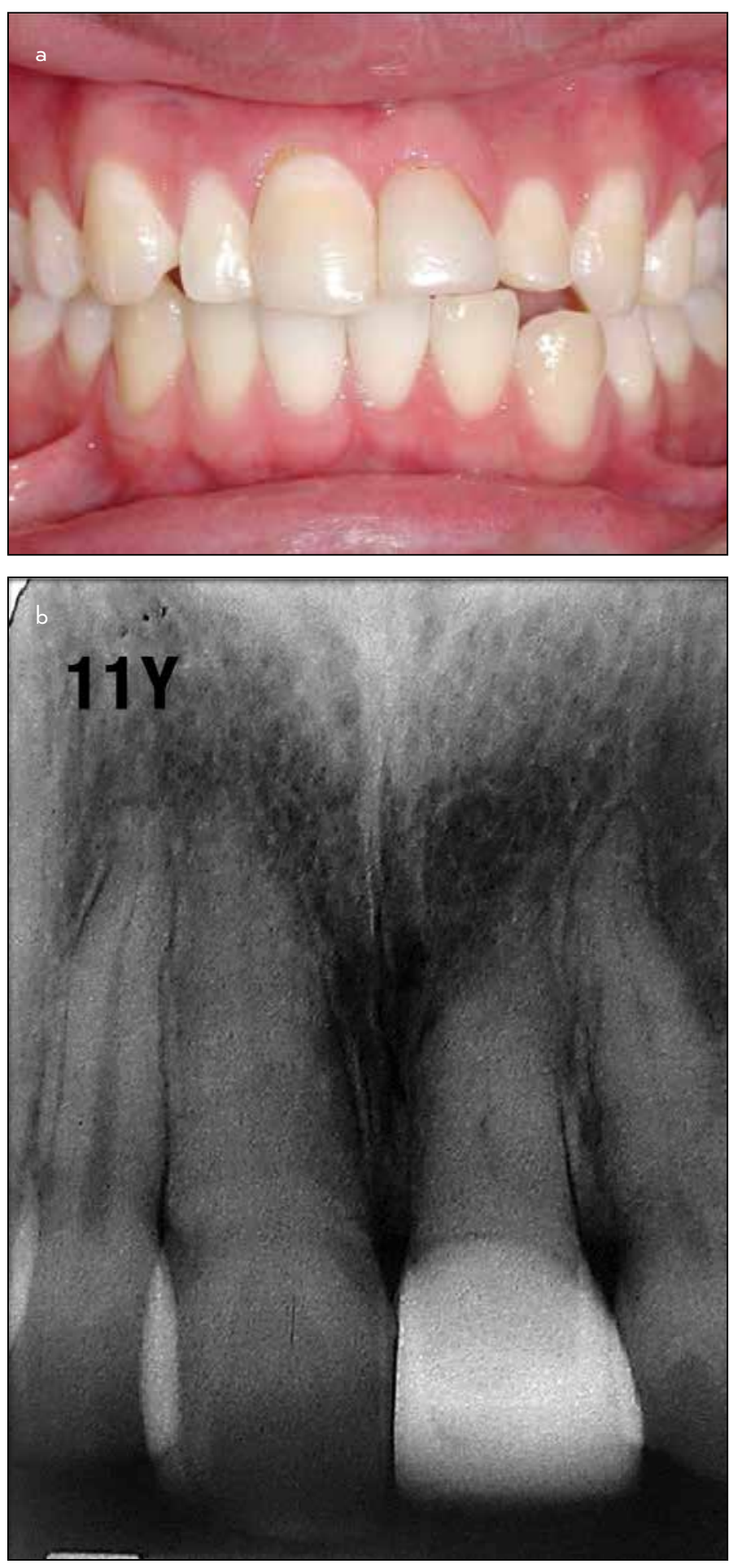

Figure 3. a, b. 11-year follow-up. Dental papillae maintain their shape and height, and healthy periodontal tissues are observed with normal alveolar bone and crest, both in width and height (a) Radiographic image shows normal periradicular tissues (b)

Two years after the procedure, the premolar responded positively, both to thermal and electric pulp tests. Radiographically, the root canal looked narrower with apposition of hard tissue, and the root had developed a distal curvature. There were no signs of periradicular or periodontal disease (Figure 2a). The appearance of the tooth was restored with a ceramic crown (Figure $2 b$ ). 

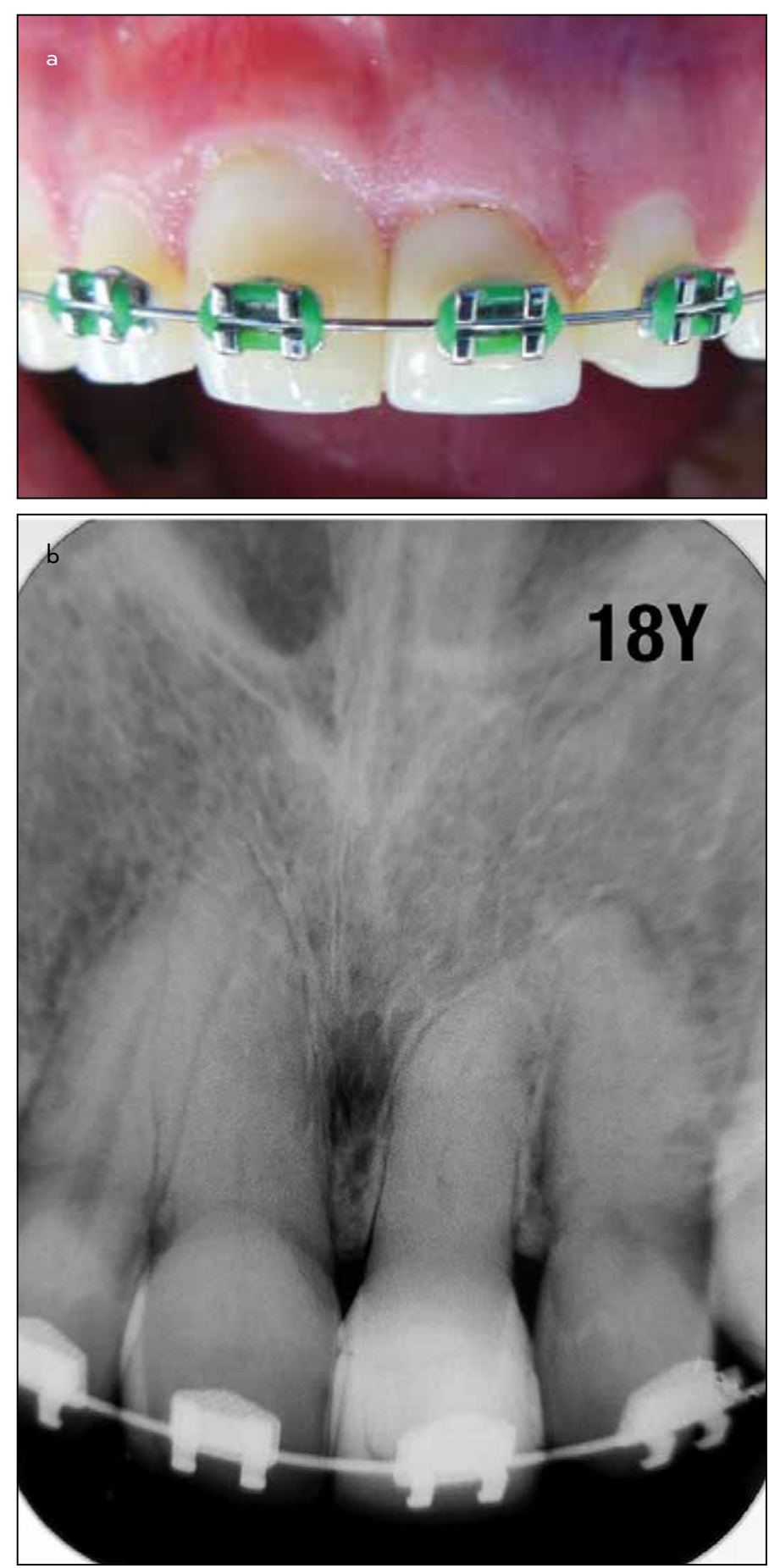

Figure 4. a, b. 18-year follow-up. Patient has undertaken orthodontic treatment, and the transplanted tooth has been moved without damage to the periodontal tissues (a) Radiographically, there is no periradicular pathosis, the periodontal ligament space has normal width, and there are no signs of inflammatory external root resorption (b)

Four years after autotransplantation, there was a minimal positive response to cold and electric pulp tests, the canal lumen had further narrowed radiographically, the bone crest height was within normal limits, and there were no signs of pathosis. A new composite resin veneer was placed on the tooth at this appointment (Figure 2c). At the 11-year follow-up visit, little change was evident relative to the 4-year visit (Figure 3a-b).
In December 2015, 18 years after initial treatment, the patient returned for a follow-up appointment while undergoing orthodontic treatment. The tooth was still responsive within normal limits to cold and electric pulp tests. Radiographically, there appeared to be hard tissue deposition in the root canal such that the canal lumen seemed to be almost completely obliterated; however, the tooth and periodontal tissues were clinically normal (Figure 4a-b).

\section{DISCUSSION}

Early loss of teeth in the anterior maxilla leads to a collapse of the alveolar bone along with alteration of craniofacial growth $(2,4,5)$. The resulting defect makes it difficult to place an implant once the patient is fully grown, meaning that they will most likely require a complicated and costly bone graft procedure (9). Additionally, it has recently been shown that school-age children with a visible untreated dental injury are more likely to experience a reduction in their quality of life compared to those who either have sustained injury but have been treated or those who have never had such an injury (10).

Several prospective and retrospective studies have shown that autotransplantation should be considered as one of the first treatment options in such cases, even in the presence of replacement resorption that could be treated with decoronation $(7-8,11)$. There are established protocols for this treatment $(3,7)$ and many retrospective and consecutive case series have been published, yet many dentists still do not consider it a predictable procedure (12).

Since the early works of Slagsvold and Bjerke $(1,2)$ in the 1970s, numerous studies have described techniques, longterm evaluation protocols, indications, contraindications, and success rates better than $90 \%$; however, these results were influenced by certain factors such as the stage of root development, presence or absence of a recipient alveolar socket, age of the patient, type of splint, time left in place, aesthetic and oral health perception, and even subsequent orthodontic treatment $(3,5,7,8,13-15)$. Recently, this technique has been described as an alternative treatment in cases of cleft palate and ankylosed upper incisor $(16,17)$.

This case did not quite follow the usually recommended protocol because of the early developmental stage of the donor tooth to be transplanted. At this developmental stage there is a high risk of affecting or damaging Hertwig's epithelial sheath during extraction and/or implantation and therefore further root development and growth could be severely affected or completely prevented $(3,5,14)$. A recent 12 -year follow up of autotransplanted teeth indicated that surgical extraction of the donor tooth was associated with a significantly higher incidence of inflammatory root resorption (18). In our case, extraction was performed very carefully to allow for preservation of the tissues, promotion of root development, and to maintain viability of the pulp. 


\section{CONCLUSION}

Available evidence shows that dental autotransplantation is a biological, conservative, and fast option that maintains the alveolar bone and crest, promotes craniofacial development and permits orthodontic movement when necessary, and is often the only treatment option to replace a lost tooth in growing children or teenagers.

This procedure is faster and less expensive than some other treatment options and, given that it has a reported success rate of $>90 \%$, with proper case selection, it should be evaluated and taught in dental schools and postgraduate programs as a biological alternative.

\section{Ethics Committee Approval: N/A.}

Informed Consent: Written informed consent was obtained from patients who participated in this study.

Peer-review: Externally peer-reviewed.

Author Contributions: Concept - W.H., L.J.W.; Design - W.H., B.K.; Supervision - B.K., L.J.W.; Data Collection and/or Processing - W.H.; Analysis and/or Interpretation - W.H.; Literature Search - W.H.; Writing - W.H.; Critical Reviews - B.K., L.J.W.

Conflict of Interest: No conflict of interest was declared by the authors.

Financial Disclosure: The authors declared that this study has received no financial support.

\section{REFERENCES}

1. Slagsvold O, Bercke B. Autotransplantation of premolars with partly formed roots. A radiographic study of root growth. Am J Orthod 1974; 66(4):355-66. [CrossRef]

2. Slagsvold O, Bjercke B. Applicability of autotransplantation in cases of missing upper anterior teeth. Am J Orthod. 1978; 74(4):410-21. [CrossRef]

3. Andreasen JO, Paulsen HU, Yu Z, Bayer T. A long term study of 370 autotransplanted premolars. Part IV. Root development subsequent to transplantation. Eur J Orthod 1990; 12(1):38-50. [CrossRef]

4. Cardona JL, Caldera MM, Vera J. Autotransplantation of a premolar: a longterm follow - up report of a clinical case. J Endod. 2012; 38(8):1149-52. [CrossRef]

5. Tsukiboshi M. Autotransplantation of teeth: requirements for predictable success. Dent Traumatol 2002; 18(4):157-80. [CrossRef]
6. Czochrowska EM, Stenvik A, Bjercke B, Zachrisson BU. Outcome of tooth transplantation: survival and success rates $17-41$ years posttreatment. Am J Orthod Dentofacial Orthop 2002; 121(2):110-19. [CrossRef]

7. Plakwicz P, Wojtowicz A, Czochrowska EM. Survival and success rates of autotransplanted premolars: a prospective study of the protocol for developing teeth. Am J Orthod Dentofacial Orthop 2013; 144(2):22937. [CrossRef]

8. Kokai S, Kanno Z, Koike S, Uesugi S, Takahashi Y, Ono T, et al. Retrospective study of 100 autotransplanted teeth with complete root formation and subsequent orthodontic treatment. Am J Orthod Dentofacial Orthop 2015; 148(6): 982-9. [CrossRef]

9. Masaki C, Nakamoto T, Mukaibo T, Kondo Y, Hosokawa R. Strategies for alveolar ridge reconstruction and preservation for implant therapy. $J$ Prosthodont Res 2015; 59(4):220-8. [CrossRef]

10. Ramos-Jorge J, Paiva SM, Tataounoff J, Pordeus IA, Marques LS, Ramos-Jorge ML. Impact of treated/untreated traumatic dental injuries on quality of life among Brazilian schoolchildren. Dent Traumatol 2014; 30(1):27-31 [CrossRef]

11. Malmgren B, Tsilingaridis G, Malmgren O. Long-term follow up of 103 ankylosed permanent incisors surgically treated with decoronation-a retrospective study. Dent Traumatol 2015; 31(3): 184-9. [CrossRef]

12. Baviz JB. Autotransplantation of teeth: A procedure that gets no respect. Oral Surg Oral Med Oral Pathol Oral Radiol Endod 2010; 110(4):441. [CrossRef]

13. Kvint $\mathrm{S}$, Lindsten R, Magnusson A, Nilsson P, Bjerklin K. Autotransplantation of teeth in 215 patients a follow up study. Angle Orthod 2010; 80(3):446-51. [CrossRef]

14. Denys D, Shahbazian M, Jacobs R, Laenen A, Wyatt J, Vinckier F, et al. Importance of root development in autotransplantations: a retrospective study of 137 teeth with a follow-up period varying from 1 week to 14 years. Eur J Orthod 2013; 35(5):680-8. [CrossRef]

15. Stange KM, Lindsten R, Bjerklin K. Autotransplantation of premolars to the maxillary incisor region: a long-term follow-up of 12-22 years. Eur J Orthod 2016; 38(5):508-15. [CrossRef]

16. Gilijamse M, Baart JA, Wolff J, Sándor GK, Forouzanfar T. Tooth autotransplantation in the anterior maxilla and mandible: retrospective results in young patients. Oral Surg Oral Med Oral Pathol Oral Radiol 2016; 122(6):e187-e192.

17. Tsurumachi T, Kuno T. Autotransplantation of a maxillary first premolar to replace an ankylosed maxillary incisor: 7-year follow-up. Int Endod J 2011; 44(9):863-75. [CrossRef]

18. Jang Y, Choi YJ, Lee SJ, Roh BD, Park SH, Kim E. Prognostic factors for clinical outcomes in autotransplantation of teeth with complete root formation: survival analysis up to 12 years. J Endod 2016; 42(2):198-205. [CrossRef] 